\title{
0 imaginário do mal no cinema brasileiro: as figuras abjetas da sociedade e seu modo de circulação
} Florence Dravet e Gustavo de Castro

\section{Resumo}

0 artigo visa observar os trajetos de circulação de algumas figuras consideradas abjetas pelo imaginário cultural brasileiro, Exu e Pomba-gira, e suas relações com o que chamamos aqui de "lixo social". Acompanhamos tais figuras através das personagens de três filmes brasileiros: Madame Satã, Cidade de Deus e Cafundó. Partindo da ideia de Circulação, segundo a qual a compreensão do trajeto efetuado pelas coisas é complexo e de difícil apreensão, recorremos a uma perspectiva histórico-social, mas também simbólico-cultural. Concluímos que 0 oculto é potencializador de uma força que permite a resistência, recorrência e ressurgência das figuras abjetas que nutrem o imaginário do mal brasileiro. Por fim, abrimos a perspectiva da alegria como um dos motores dessa força potencializada pelo oculto.

\section{Palavras-Chave}

Imaginário do Mal. Abjeção. Pomba-gira.

Cinema. Circulação.
Florence Dravet I flormd@gmail.com Doutora em Ciências da Linguagem pela Universidade de Paris 3 Sorbonne Nouvelle. Professora do Mestrado em Comunicação da Universidade Católica de Brasília (UCB).

Gustavo de Castro I gustavocastroesilva@gmail.com Doutor em Antropologia pela Pontifícia Universidade de São Paulo (PUC). Professor do Programa de Pós-graduação em Comunicação da Universidade de Brasília (UnB).

\section{Introdução}

A historiografia do cinema brasileiro possui uma ampla filmografia em torno daquilo que chamaremos aqui de "sujeira social" do Brasil, os elementos que a sociedade brasileira considera como impróprios (KRISTEVA, 1980) e que rejeita. 0 cinema parece ser uma das formas de expressão que favorece certos não-ditos da sociedade e da cultura neste país. É o cinema mais que a literatura, provavelmente, que se assume no Brasil, particularmente desde os anos 1950, como lugar de expressão da realidade histórica, social e cultural complexa, marcada por idiossincrasias culturais, religiosas e sociais dificilmente expressas fora da ficção e do seu poder ao mesmo tempo evocador e revelador.

Podemos, desde já, citar alguns dos filmes que denotam essa característica no cinema brasileiro: o Cangaceiro (Lima Barreto, 1953), Deus e o diabo na terra do sol (Glauber Rocha, 1964), Vidas secas (Nelson Pereira dos Santos, 1963), Pixote (Hector Babenco, 1981), O homem que virou suco (João Baptista de Andrade, 1981), 
Orfeu (Cacá Diegues, 1999), Carandiru (Hector

Babenco, 2003), A festa da menina morta

(Matheus Nachtergaele, 2008), Besouro (João

Daniel Tikhomiroff, 2009), Girimunho (Clarissa

Campolina, Helvécio Marins Jr., 2011), Faroeste

caboclo (René Sampaio, 2013).

Em todos esses filmes, os protagonistas não são heróis modelos, mas pobres, marginais, excluídos, gente fugindo da seca do Nordeste; negros escravos e seus descendentes indesejáveis após a abolição da escravidão; justiceiro da causa dos humilhados; bruxos, adivinhos e outros místicos dotados de missões espirituais duvidosas aos olhos de um positivismo oficial eurocentrado; cruéis bandidos formados à dureza das condições de vida em uma sociedade por demais injusta; prostitutas e travestis encarnando toda a sorte de depravações sexuais que nenhuma boa moral pode admitir. Tais personagens formam parte do conjunto daquilo que consideramos como as figuras abjetas da sociedades.

Como Julia Kristeva (1980) bem disse em Pouvoirs de L'horreur - Essai sur l'Abjection nunca nos livramos totalmente da sujeira. Ela sempre volta, como em um ciclo em movimento que vai da rejeição e exclusão no domínio do oculto, passando por diversas formas de resistência e sobrevivência e, inevitavelmente, volta dotada de uma força vital recrudescente. Isso se verifica para os dejetos naturais, que se recompõem como húmus ao solo, se verifica com os dejetos industriais de que buscamos nos desfazer, e se estende para a "sujeira social". Esse movimento circular e cíclico inevitável da sujeira social que nomeamos circulação, será o objeto do nosso olhar sobre 0 cinema brasileiro e o imaginário do mal.

A noção de circulação busca corrigir o fato de que as coisas são apreendidas em uma parte reduzida do seu trajeto, a compreensão do circuito efetuado pelas coisas é complexa e dificilmente alcançada. Em geral, as coisas só são apreendidas por um momento e se perdem no caudal do seu curso. A noção de circulação comporta várias possibilidades e muitas variantes, pois é a noção de circularidade aberta que está em jogo, na forma de uma espiral. A fenomenologia da forma esférica produziu uma teoria desenvolvida em três volumes por Peter Sloterdijk, (1998, 1999 e 2004), onde 0 filósofo propõe um pensamento em movimento que integra a razão, a poesia e a arte. A simbologia da forma circular é um tema recorrente na mitologia e na espiritualidade. Na mitologia africana, há uma divindade da forma circular, que é também a divindade do consumo no mercado, das trocas e da circulação: Exu Akesan. É ele que garante a circulação entre as diferentes esferas da existência. Mas esta divindade não é apenas exterior ao homem, faz parte dele. Desta forma, todo indivíduo conhece e experimenta a manifestação íntima desta divindade que rege a circulação de todos os fluxos vitais no corpo e preside ao movimento.

A chamamos então de Exu Bará, o rei do corpo.

Edgar Morin (1962) entende a própria cultura a partir da noção de circulação de imagens, 
símbolos, ideologias, mitos, referentes tanto à vida prática quanto à vida imaginária. As culturas (religiosa, nacional, humanista e de massa) também circulam entre si, se alimentam e se retroalimentam. Em seu livro O Método IA Natureza da Natureza, Morin (2002) define que nossa sociedade sempre possuiu modos de circulação diversos: vias oficiais, rotas clandestinas, cada qual com suas alfândegas, cancelas e zonas aduaneiras. Morin propõe um "método de articulação circular entre diferentes saberes", que ele concebe também como uma forma de retroalimentação entre saberes que pode ir ao infinito e permite a durabilidade, resistência e crise de um sistema aberto.

Aqui, a noção de circulação nos permitirá observar a maneira como as figuras abjetas da sociedade se apresentam no cinema, mas, sobretudo como resistem e ressurgem, ou seja, como circulam na sociedade brasileira. Para tanto, concentraremos nossa reflexão em torno de duas figuras abjetas que consideramos emblemáticas: Exú e Pomba-gira; e a maneira como o cinema brasileiro as apresentou em três filmes: Cafundó (Paulo Betti e Clovis Bueno, 2005), Madame Satã (Karim Ainouz, 2002) e Cidade de Deus (Fernando Meirelles, 2002).

Os termos Exu e Pomba-gira exigem sempre novas retomadas. Trata-se de duas figuras da Umbanda e da cultura popular do Brasil. Do ponto de vista religioso, Exu é o Orixá do movimento, da comunicação e mensageiro entre homens e deuses. Exu é também o nome atribuído aos espíritos guardiões e protetores que acompanham e cuidam dos humanos. São seres de luz que conhecem as trevas, o que lhes dá a característica ambivalente de serem transitantes entre 0 bem e o mal. Do ponto de vista da cultura popular brasileira, Exu é um espírito do mal, por vezes confundido como o diabo ou o demônio. Apresenta-se como um homem da noite, habitante das encruzilhadas e dos cemitérios, ora bandido, ora mendigo, ora malandro. Gosta de brincar, cantar, dançar, gargalhar, fumar e beber. Frequenta bares e cabarés, é sedutor e articulador, por vezes, vulgar e perigoso. Responde prontamente aos pedidos de vingança, de dinheiro e de emprego. Guarda e protege aqueles que 0 cultuam. A pomba-gira é a versão feminina deste mesmo personagem. Acrescida de novas imagens de impureza. Ela é vista como prostituta, feiticeira, ao mesmo tempo, bela, sedutora e perigosa. A ela se recorre quando de problemas sentimentais, afetivos, sexuais e de feminilidade.

Espíritos do mal, bandidos, mendigos, prostitutas, todas figuras abjetas da "boa sociedade" brasileira e de sua moral. Para compreender como essas figuras aparecem nos três filmes escolhidos e constituem uma das manifestações do imaginário do mal no Brasil, percorreremos o trajeto da circulação que efetuaram de um ponto de vista, histórico, cultural e religioso. Nosso artigo será, portanto, organizado em três etapas: 
Pensaremos o Brasil colonial como território do abjeto: território do índio, do "selvagem" antropófago, do negro escravo, e de todos os excluídos do reino de Portugal e de Espanha, condenados entre os séculos XVI e XVIII ao exílio nesta terra "infernal" (SOUZA, 1993). Veremos que, desde as origens da constituição da cultural e da civilização brasileira, uma cisão se estabelece entre a "boa sociedade" e seu discurso moral e 0 universo efervescente dos rejeitados e excluídos da sociedade. Se Souza fala em "inferno atlântico" ao referir-se ao período colonial, a literatura francesa do século XIX continua explorando essa imagem do Brasil como "terra do mal" (BRZOZOWSKI, 2001).

Veremos em seguida que tipo de relações se estabelecem entre os dois universos acima citados. E como tudo aquilo que a "boa sociedade" produziu de sujeira social finda por retornar-lhe na forma dessas figuras abjetas que a fascinam e a repugnam. Aquilo que excluímos e que calamos reaparece nas imagens e é o cinema, com toda a sua força imaginária, que trata das "faces inconfessas do Brasil" (PRANDI, 1996) espelhando imagens agora inegáveis.

Por fim, veremos como se efetua de uma maneira própria ao Brasil, à complexidade de sua cultura híbrida, marcada desde as origens por fortes tensões sociais, a passagem do inconfesso para 0 oculto. E que é precisamente nesta passagem, na transformação dos territórios da exclusão moral em território do oculto, que a abjeção adquire sua força vital e se vê reconfigurada: 0 bandido tornase espírito do mal, mas também protetor desta gente pobre; a bruxa torna-se elegante feiticeira, protetora do amor desta gente.

0 lixo social se recicla. Também o "lixo" espiritual. No conjunto das religiões populares brasileiras, a Umbanda é a única a permitir a inclusão destes "espíritos do mal" justamente por não apostar nas dicotomias (bem/mal; céu/inferno; vida/ morte). Ao supostamente incluir o "mal" em seu sistema filosófico, a Umbanda não entende a sujeira social ou espiritual, senão integrada na ambivalência "corrupção/renascimento"; "abjeção/ pureza"; "obstáculo/santidade" (KRISTEVA, 1980, p. 82). Sendo assim, a que noção de mal nos referimos aqui? Trata-se de uma noção que vai além da dicotomia ocidental bem/mal, mas que é ncessariamente influenciada por ela. Diremos com Michel Maffesoli (2004, p. 40):

Nunca se dirá o suficiente a respeito de quanto a separação divina entre trevas e luz marcou profundamente a consciência ocidental. Toda a temática da emancipação moderna repousa nesta separação [...]. É a partir deste corte radical que se elabora 0 conflito metafísico entre o bem e 0 mal. Para 0 cristianismo, religioso ou laico, não existe mais equilíbrio entre essas duas entidades. Na teoria agostiniana, 0 mal não tem realidade em si, não passando de uma 'privação do bem' (privatio boni).

Este "conflito metafísico" gerou a incapacidade de integrar bem e mal em um mesmo sistema ou, dito de outro modo, de reunir espiritualidades ou modos diversos de sentir as realidades que 
nos cercam. Este "conflito" estendeu-se em todo o conhecimento ocidental e impossibilitou um pensamento sobre a integração dos saberes.

Por isso mesmo, também nos interessa aqui a ambivalência segundo o qual "É ao aceitar o mal em suas diversas modulações que podemos reencontrar uma certa alegria de viver" (MAFFESOLI, 2004, p. 20). Não estaria aí 0 sentido de Exu e Pomba-gira, seres abjetos que habitam nossa sociedade e nosso corpo, que rejeitamos e que se manifestam ainda assim, no riso, na alegria, na tomada do corpo, na sexualidade unida à sacralidade?

\section{Brasil: terra do mal}

Em 1590 o padre jesuíta José de Acosta (apud SOUZA, 1993) escreve a respeito das práticas de idolatria dos índios então percebidas como uma influência diabólica: "Expulso pela chegada de Cristo, o demônio se refugiou nas índias, fazendo delas seus bastiões." A idolatria é para ele o começo e 0 fim de todos os males. E as Índias, o lugar de refúgio do demônio, terra onde os nativos são vítimas das ilusões fantasiosas e das perseguições que 0 Maligno lhes inflige, e de quem os missionários jesuítas deverão afastá-los a qualquer preço. As práticas antropofágicas, as danças rituais, as oferendas - humanas ou não - parecem então particularmente horríveis e demoníacas aos olhos católicos e devem ser combatidas pela difusão da fé cristã. 0 caráter cambiante e plural das práticas indígenas aparece também como uma profusão caótica, desordenada e sem sentido.
Todavia, a Igreja portuguesa nunca empreendeu, no Brasil, uma verdadeira política de erradicação do mal e da influência demoníaca. Não houve na colônia portuguesa escritos relevantes sobre as superstições, nem sobre as questões relativas à liberdade e à humanidade dos índios, como os dos missionários espanhóis (Las Casas, Acosta, Odegardo), nem a respeito do comportamento dos próprios colonos. Ao contrário, as missões jesuítas e as visitas inquisitoriais na colônia portuguesa sempre se depararam e toleraram a presença de práticas populares de blasfêmios, desprezo e deboche em torno dos nomes dos santos, de Deus, do clero e dos sacramentos e, ainda, confrarias indígenas biculturais tais como a confraria do Jaguaripe, no Estado da Bahia. Esta adotava certos elementos da fé católica ao mesmo tempo em que mantinha ritos e práticas indígenas: bebidas alucinógenas, danças, pinturas corporais etc. Ademais, as práticas religiosas populares dos colonos misturavam-se e se confundiam com as práticas mágicas e de bruxaria indígenas e africanas. Em seu estudo sobre demonologia e colonização portuguesa entre os séculos XVI e XVIII, Laura de Mello e Souza (1993) considera três fatores principais de miscigenação das práticas mágicas: a chegada de muitos acusados de bruxaria, condenados ao degredo na colônia; o encontro entre estes e as práticas indígenas locais; a influência de práticas africanas toleradas por um sincretismo de faixada.

De acordo com as visitas à Bahia, um escravo de Guiné, de nome André Buçal lia a sorte em panelas e fervedouros por volta do ano de 1587. 
A partir de então, as referências são cada vez maiores: em torno de 1610, a feiticeira Maria Barbosa, protegida do governador do estado da Bahia, Diogo de Menezes, agia em concordância com a negra Cucana que fazia pós com raspas de certas raízes. Em 1616, brancos utilizavam os saberes de seus escravos negros para obter a cura de males diversos entre seus escravos ou mesmo em sua própria família (SOUZA, 1993, p. 54).

Quanto às práticas indígenas miscigenadas com as crenças cristãs, Souza (1993, p. 56) conta que "Antonio, por exemplo, que teve um papel fundamental na confraria dos Jaguaripe, fugira da aldeia missionária jesuíta Tinharé, na Capitania de Ilhéus, onde fora instruído no catolicismo" e que:

Dona Maria da Costa, dona de engenho, declara quando da investigação inquisitorial que 'naquele tempo, quando a confraria veio ter em sua propriedade, durante mais ou menos dois meses, ela pensava que isto não podia ser coisa do demônio, mas coisa de Deus, pois que carregavam cruzes de que o diabo foge e que faziam reverências à cruz e utilizavam rosários e tratavam com a virgem Maria'.

Havia, portanto, no Brasil colônia dos séculos XVI a XVIII, por um lado uma maioria popular, oficialmente cristã, mas de práticas diversas e miscigenadas e, por outro lado, uma minoria constituindo o núcleo da religião oficial praticada por bons cristãos, que se confessavam e comungavam com frequência, iam à missa regularmente e viviam conforme as exigências da lei católica portuguesa. Estes últimos constituíam a norma, aquilo que chamamos acima de "boa sociedade", contrastando com a sujeira social.
A respeito da condição particular das mulheres, Del Priore (2009) descreve minuciosamente a barreira colocada pela igreja entre as mulheres que cumpriam perante a igreja seu papel de mães cristãs ("As santas mães") e o conjunto daquelas cuja maternidade era vista como ilegítima: as depravadas, ou seja, todas as outras mulheres e sua prole. A Igreja e seus diversos tribunais contavam com o bom senso da "boa sociedade" cristã para colaborar na construção de uma sociedade onde homens e mulheres, mas principalmente estas, poderiam fundar famílias estáveis, de valores seguros, onde a educação teria um papel fundamental. 0 resultado é descrito por Del Priore em uma enumeração de casos de acusações e de julgamentos em torno dos maus elementos da sociedade. Acusava-se, investigava-se, interrogavase e, na maioria das vezes, as mulheres - e os homens enquanto cúmplices - eram considerados culpados de crimes morais. 0 importante então era minimizar os desvios, compensando-os mediante um código de punições e perdões muitas vezes de ordem pecuniária. Ao longo desse processo, a igreja tratou de caracterizar as práticas transgressoras correntes das mulheres pertencentes às classes subalternas e de transformá-las em excesso; daí 0 estigma da puta reservado às mulheres que não seguiam a norma social.

No que concerne à pomba-gira 0 estudo de Marlise Meyer (1993) mostra a forma como se deu a passagem da bruxaria portuguesa para a feitiçaria brasileira, miscigenada e associada à imagem depreciativa da puta. Passagem esta marcada por 
uma realidade histórica, mas também pela força de um imaginário do mal inspirado pelo universo da magia nos dois continentes.

A história da Maria Padilha é emblemática dessa passagem. No Brasil, falar em Maria Padilha é falar na pomba-gira mais temida e respeitada do país. Sua história data dos romances relativos à história espanhola e do reino de Pedro I de Castela, dito Pedro, 0 Cruel (século XIV). Sua crueldade seria atribuída às mortes infligidas aos seus irmãos, sua mãe e sua esposa sob influência de uma mulher má, a belíssima e vingativa dona Maria de Padilla. Pertencente à nobreza de Castela $\mathrm{e}$ dotada de poderes mágicos, teria ela sido capaz de enfeitiçar o rei a ponto de fazê-lo esquecer de seus deveres conjugais e de ludibriá-lo com sortilégios, transformando um cinto de pedras preciosas, ofertado pela rainha, dona Blanca, em horrível serpente. (Romanceiro de Quevedo In Biblioteca de Autores Espanhóis, 1945). Além das histórias do imaginário popular e literário, a Sintesis de historia de España (Beretta y Ballesteros, apud Meyer, 1993) confirma a existência de Maria de Padilla e a paixão do rei dom Pedro.

No século XVII, o nome de Maria Padilha figura nas palavras encantatórias e de conjuro de três mulheres acusadas de feitiçaria e julgadas pelos tribunais da inquisição de Portugal. Trata-se de Luisa Maria (processo 7840, ano 1640), de Manuela de Jesus (processo 761, ano 1662) e de Maria de Seixas (processo 74, ano 1673). Todas as três invocam em seus conjuros os poderes de "Maria Padilha e toda a sua quadrilha". Um exemplo extraído dos arquivos nacionais da Torre do Tombo de Lisboa confirma: "Dona Maria Padilha e toda a sua quadrilha, traga-me fulano pelos ares e pelos ventos. Marta, a perdida, que pelo amor de um homem foi ao inferno, rogo-lhe de conceder um pouco do seu amor a fulano, que não consiga dormir, e que não tenha repouso até que a mim se junte" (processo 7840, Luisa Maria, autoda-fé de 1640). A amante má do rei de Castela, Maria de Padilla, tornou-se aqui objeto de conjuro do mal para fins amorosos e de "amarração".

Souza (1986) em suas pesquisas nos arquivos de inquisição portuguesa do século XVIII, a respeito das mulheres degredadas para o Brasil, se depara novamente com o nome de Maria Padilha, nas palavras da feiticeira Antonia Maria, que jurava por "Barrabás, Satanás, Caifás, Maria Padilha e toda a sua quadrilha”. Antonia Maria, que fora degredada para Angola pelo tribunal da inquisição em 1713, chegou a Pernambuco em torno do ano de 1715, acompanhada de outra feiticeira, Joana de Andrade - com a qual havia aprendido tudo ainda em Beja, Portugal. Mais tarde, as duas mulheres brigaram por ciúme relacionado a prestígio profissional. Joana de Andrade, acusa então Antônia de ir longe demais em suas práticas. Os relatos dos conhecimentos e das ações mágicas de Antônia incluem numerosas encantações e elementos provindos dos conhecimentos indígenas do Norte do país, tais como "as encantação da cabra preta", praticada no estado do Pará, do Rio Grande do Norte e da Paraíba, de acordo com os estudos de 
Mário de Andrade (1963). Tudo indica que os ares da colônia contribuíram para acentuar a vocação demoníaca das mulheres (SOUZA, 1986).

Deduzimos que foi por intermédio das mulheres portuguesas acusadas de feitiçaria e degredadas para o Brasil que Maria Padilha faz sua entrada no universo da magia e da feitiçaria popular no país. Por um longo processo de assimilação e aculturação, Maria Padilha torna-se pomba-gira, entidade de Umbanda, sendo figura central no universo dos exus. Nota-se que, em muitos relatos, ela é percebida como uma mulher branca, provinda da nobreza: "Maria Padilha dizem que foi uma grande dama, da nobreza mesmo; parece que era espanhola e que tinha modos" (MEYER, 1993, p. 113). No entanto, 0 universo da magia no Brasil está longe de ser branco. É até acusado de ser índio ou africano, mas a verdade é que não pertence à população alguma em particular, nem a nenhuma cor ou religião. 0 universo da magia no Brasil é plural e sobretudo popular. Pertence a todos e integra saberes oriundos de tradições diversas: indígenas de diversas regiões, africanos de várias nações, europeus de diversas origens, inclusive de influências mouras, que a cultura ibérica medieval absorveu por muito tempo. De acordo com Lody (1982, p. 19):

Bombo-gira é uma bacante. Poderosa e conhecedora da magia. Às vezes é espanhola, outras vezes cigana, às vezes dançarina da praça Mauá, ou mulher das zonas do baixo meretrício. E assim vão as especulações em torno da personagem. 0 interdito, 0 impossível, segundo as normas modelares da sociedade, não conhece nenhum limite, nem ético, nem moral.
Aí reside toda a questão, ligada à cisão originária na formação da população e da cultura brasileira de que falamos acima: uma parte minoritária em número, cujo poder hegemônico domina indubitavelmente os discursos oficiais com sua moral cristã, relega ao domínio da sujeira social tudo o que pode ter relação com a outra realidade, aquela do mal, dominada pelo diabo e seus agentes: índios, negros, feiticeiros, putas, bandidos e mendigos.

\section{As figuras inconfessas do Brasil no cinema}

Para melhor se compreender as faces inconfessas do Brasil faremos uma leitura de três filmes que tratam de maneira mais ou menos direta as figuras de Exú e Pomba-Gira de que tratamos acima, seu papel na sociedade e 0 lugar que ocupam na esfera da sujeira social. Mostraremos como essas figuras de abjeção se reconstituem na tela, chamando atenção da sociedade que as rejeitou. Reconstituição feita de maneira artística e ficcional, mas também realista e crítica. Se não constituem heróis no sentido estrito, as figuras de abjeção são todavia protagonistas de narrativas que fazem pensar.

\subsection{Cidade de Deus: de Dadinho a Zé Pequeno}

A dualidade "corrupção/renascimento" é 0 objeto do filme Cidade de Deus, que conta a trajetória de três amigos de um mesmo bairro periférico da cidade do Rio de Janeiro. 0 primeiro, 
Dadinho, decidido a fazer valer o seu espírito de vingança e crueldade é rabtizado por um médium caracterizado como um Exú (guias, charuto, roupa preta e vermelha, instrumentos rituais fálicos, voz, vocabulário), que lhe promete sua proteção e lhe dá seu novo nome: "Zé Pequeno", o que lhe garantirá glória e poder. Assim, Zé Pequeno tornase o maior e cruel traficante do Rio de Janeiro, mas também protetor dos habitantes do bairro. Será capaz de matar as crianças inoportunas, liquidar seus próprios comparsas e de toda a sorte de crueldades para garantir seu poder, ao mesmo tempo em que asseguram proteção daqueles que 0 respeitam.

0 segundo, Bené, é o melhor amigo de Zé Pequeno, o único em quem confia, que exerce papel de pacificador entre os habitantes do bairro e a zona rica da cidade. Bené tenta integrar funkeiros, sambistas, crentes, amantes da black music, os cocotas (burgueses) e o próprio Zé Pequeno. Bené oferece uma festa no morro no dia em que trocará 0 crime pelo amor de uma mulher. 0 sonho de redenção e de vida regenerada ao lado de seu amor vem acompanhado da tragédia. Bené é assassinado ao defender Zé Pequeno em uma discussão. 0 renascimento de Bené não acontece. ou se ocorre é pelo sacrifício deste.

Um dos personagens mais explorados do filme é Buscapé, que preferia a praia, a maconha e sua máquina fotográfica ao mundo do crime. Não que fosse incorruptível, seu problema era que não tinha vocação para a "bandidagem". Foi demitido de supermercado por ser pobre, morador da Cidade de Deus. Sua sujeira social deve-se a um fator geográfico, o de morar na periferia. Tentou vários caminhos para não entrar no crime. Um desses caminhos é o de fotógrafo de jornal. Por morar na Cidade de Deus, tem a oportunidade de registrar uma foto, pela casualidade de estar no lugar certo na hora certa. Sua fama no fotojornalismo cresce e faz ele "se dar bem" com uma garota no final do filme. Buscapé aparece recompensado pelo fato de não apostar numa vida de corrupção e crime. Buscapé é o único dos três a ter sua atitude recompensada. Zé Pequeno, o protegido de Exú, acabou morrendo como um bandido, Bené morreu como mártir. Quanto à Cidade de Deus, passou as mãos de um novo traficante.

\subsection{Madame Satã: de João Francisco à Madame Satã}

Observaremos agora o filme Madame Satã a partir da dupla "abjeção/pureza". 0 filme conta a história de João Francisco dos Santos Sant'Anna (1900-1976), conhecido a partir de 1942 como Madame Satã, depois de desfilar no bloco-derua Caçador de Veados, no carnaval do Rio, com fantasia inspirada em filme homônimo de Cecil B. DeMille. Negro, homossexual, transformista, Madame Satã é visto como personagem emblemático da vida noturna e marginal carioca na primeira metade do século XX, por reunir em sua imagem o puro e o impuro, o forte e 0 fraco, 0 masculino e o feminino, passivo e ativo da vida social brasileira. Santos fora criado numa família 
de 17 irmãos. Diz-se que ainda menino chegou a ser trocado por um cavalo. Viveu em Recife e posteriormente mudou-se para o Rio. Analfabeto, começou a entregar marmitas. Fez pequenos serviços de cozinheiro. Dotado de uma índole irônica e extrovertida, encantou-se pelo carnaval carioca. Frequentador assíduo do bairro da Lapa, onde também morava - conhecido reduto carioca da malandragem e boemia da década de 1930. Na Lapa, Santos também trabalhou como segurança de casas noturnas. Ficou conhecido por cuidar das prostitutas para que não fossem vítimas de estupros e agressões. Era exímio capoeirista, lutou diversas vezes contra mais de um policial, geralmente em resposta a insultos que tivessem como alvo mendigos, prostitutas, travestis e negros. Faleceu logo após a sua última saída da prisão, em abril de 1976. As figuras da abjeção marcam as imagens de Santos.

0 filme mostra várias cenas em que Madame Satã cuida de um bebê, a filha de sua amiga prostituida. Em outra cena, Madame Satã chora a dor de amor. Logo mais chorará a morte do homem que amou. 0 filme mostra também claramente 0 pertencimento de Madame Satã à religião popular dos Orixás que a boa sociedade brasileira não aceita: na entrada da sua casa, um altar com velas vermelhas e uma estátua de santo. Em seu pescoço uma guia vermelha de Iansã e nos dedos, um anel com búzio. 0 vermelho da vela e da guia carregam a significação do santo de que Madame Santã é filho. Ele afirma claramente: "Sou filho de Santa Bárbara e São Jorge" e acrescenta em tom de deboche "E devoto de Josephine Backer", famosa dançarina do Moulin Rouge, que ele admirava e que o inspirava em seus números de transformismo. 0 personagem coloca num mesmo plano a santa e a cantora de cabaré, reiterando a ideia de duplo pertencimento, puro e impuro, das figuras abjetas da vida social brasileira. Duplo pertencimento que se verifica no nome que João Francisco Santos assume publicamente: "Madame Satã" evoca o prestígio das cortesãs francesas e 0 personagem diabólico de Satã, elemento provocador, polêmico e caótico ao qual Exú é associado.

Podemos dizer que o personagem de Madame Satã é a própria ambivalência. Encarna ao mesmo tempo Exú e Pomba-gira em um corpo masculino. Morto em 1976 por maus tratamentos recebidos em sua última prisão, Madame Satã permanece no imaginário coletivo e popular como figura emblemática dessa ambivalência transformista, caótica, inclassificável, encarnada na pele de um homem negro, pobre, analfabeto e homossexual. Sem dúvida, uma figura de abjeção cujas imagens recorrentes emocionam ao mesmo tempo que causam um profundo mal-estar.

\subsection{Cafundó: de João de Camargo a Nhõ João}

Em Cafundó vemos bem retratada a relação "obstáculo/santidade". No filme se manifesta com toda a sua força, a figura de João de Camargo (1858-1942), ex-escravo, médium, considerado santo popular, milagreiro e preto-velho. 0s 
pretos-velhos assumem na Umbanda a imagem de escravos e se apresentam como purificados pela dor da existência que tiveram.

João de Camargo viveu em Sorocaba, no Estado de São Paulo, onde construiu a igreja do Bom Jesus do Bonfim das Águas Vermelhas. Nascido escravo, foi batizado com o sobrenome de seu antigo dono. Após a abolição da escravidão mudou-se para Sorocaba, onde trabalhou como cozinheiro, militar, trabalhador de lavoura e de olarias. Saiu da cidade por duas vezes e, numa dessas vezes, conheceu Rosário do Espírito Santo, que veio a ser sua esposa. Ambos viveram juntos por apenas cinco anos, logo se separando. Durante a vida, Nho João, como viria a ser conhecido mais tarde, teve problemas com 0 alcoolismo, que 0 impediria de assumir plenamente sua missão espiritual. Em 1906, teria tido uma visão que o curou do vício da bebida, fazendo-0 dedicar-se completamente ao projeto de fundar sua igreja. Antes mesmo de completar trinta anos, já praticava curas, 0 que gerou um processo por curandeirismo em 1913. Para se proteger registrou sua igreja como Associação Espírita e Beneficente Capela do Senhor do Bonfim, reconhecida como pessoa jurídica em fevereiro de 1921.

Paulo Betti mostra em seu filme a figura da esposa de João de Camargo, Rosário do Espírito Santo, no papel de pomba-gira, como instigadora da sua fé e da sua missão. Através dos "obstáculos" que enfrenta, ou seja, os desafios do coração e as dores de amor por causa de Rosário, a perseguição política e espiritual que sofria em Sorocaba, assim como a superação dos problemas pessoais, se manifesta toda a sabedoria do homem que aceitou o sofrimento. Aqui a figura de abjeção é santificada.

\section{Modos de circulação do mal e das figuras de abjeção}

Mostraremos aqui os trajetos efetuados pelas figuras do mal no imaginário da cultura brasileira, imaginário hoje alimentado pelas imagens cinematográficas e as narrativas que veiculam, reflexos indubitáveis daquilo que a sociedade brasileira busca negar. Como anunciamos na introdução, tudo o que se rejeita, os dejetos e a sujeira da qual queremos nos livrar volta cedo ou tarde, após longo percurso de reciclagem. Veremos abaixo como este trajeto se efetua na obscuridade. Por enquanto, consideramos a tríade "corrupção/ renascimento", "abjeção/pureza" e "obstáculo/ santidade" como conjunto de ambivalências compreendidas não como oposições, mas como percursos de transformação que podem nos auxiliar na interpretação dos filmes propostos.

Uma demonstração evidente dessa circulação aparece na análise dos percursos dos personagens centrais dos três filmes estudados, simbolizados pela mudança de nome: Dadinho torna-se Zé Pequeno, João Francisco torna-se Madame Satã e João de Camargo torna-se Nhõ João. 0 batismo marca aqui simbolicamente 0 efeito de uma transformação social. Dadinho, menino 
embrutecido pela sua condição social de negro, feio, morador de um bairro periférico, cuja vida é marcada pela violência cotidiana, transformase em um perigoso bandido. João Francisco dos Santos, pobre, analfabeto, negro e homossexual torna-se a bela e sedutora Madame Satã, por fim, João de Camargo, ex-excravo, pobre e rejeitado pelo sistema econômico e social do país, traído por sua mulher, torna-se o preto-velho Nhõ João.

Os nomes mudam, os personagens se transformam, mas os elementos culturais persistem. No plano da cultura e das práticas sociais identificamos nos filmes estudados, cinco traços associados às figuras de abjeção, marcos da perenidade de uma cultura mesmo quando esta é marcada pela exclusão e denegação:

a) a presença de Exú e Pomba-gira: aquele que rebatiza Zé Pequeno em Cidade de Deus, prometendo-lhe poder e glória; aquela que reconhecemos em Madame Satã quando se traveste de mulher e canta no cabaré; aquela que encontramos na personagem Rosário do Espírito Santo, do filme Cafundó.

b) a presença dos deuses africanos sincretizados: Exú, em Cidade de Deus; Iansã e Ogum (Santa Bárbara e São Jorge, em Madame Satã), Oxalá ou o Senhor do Bomfim, em Cafundó; mas também, em Cafundó, Xangô, divindade de justiça ou São Jerônimo, Oxum, deusa do amor ou Nossa Senhora da Conceição. c) as práticas mágicas, os milagres e toda sorte de superstições: utilização de guias e talismãs tanto por Zé Pequeno como por Madame Satã, utilização de óleos e essências milagrosas; realização de oferendas por Nhõ João; vozes e visões espirituais em Cafundó; altar com vela e imagens em Madame Satã.

d) os prazeres das drogas, do álcool e do sexo: a droga que domina todos os personagens e motiva toda a narrativa, em Cidade de Deus; 0 alcoolismo de João de Camargo, em Cafundó; o comércio do sexo e a prostituição, em Madame Satã; a sedução e 0 sexo de João de Camargo com Rosário.

e) a alegria, o riso e a festa: em Cidade de Deus é pela música e pela dança que a alegria dos moradores do bairro se expressa na festa organizada por Bené; é no espetáculo de música e dança no bar de um amigo que Madame Satã transmite sua alegria a todos os frequentadores do bar, inclusive ao proprietário; E é numa festa de cidade do interior que João de Camargo encontra a pomba-gira. Nos três casos a festa conduz à perdição: Bené é assassinado na noite de sua festa de despedida; a noite de Madame Satã termina com uma cena de violência que fará dele um criminoso; e o encontro de João de Camargo com a Pomba-gira na festa está na origem de sua perdição no alcoolismo durante um longo período de sua vida. 
Vimos que "É ao aceitar o mal em suas diversas modulações que podemos reencontrar uma certa alegria de viver", diz Maffesoli (2004, p. 20). E retomamos aqui o tema do riso. Desse riso que permite assumir o mal como uma das constantes da vida dos homens. Fracos e corruptíveis, é bem verdade que os homens correm o risco de decair no mais profundo de suas trevas, como Zé Pequeno e, de certa forma, João de Camargo no seu período de alcoolismo. Mas a alegria também pode ser um caminho de felicidade: rir, cantar e dançar, para não cair nas sombras, como Madame Satã.

É precisamente quando um dos personagens acusa Madame Satã de todos os males da sociedade, depois de seu espetáculo, que a alegria se transforma em horror e que Madame Satã se enche de ódio e de sentimento de vingança e se condena a ser um criminoso, assassino, prisioneiro de sua condição social. Ele mata seu agressor, aquele que com o pretexto de uma "boa moral" 0 impede de rir, de cantar e de dançar, de ser a mulher de seus sonhos.

\section{Conclusão}

Percebemos que se, ao final de um percurso e modo de circulação, todas essas práticas persistem, se esses personagens permanecem, se tudo aquilo que desde a colonização, e ainda hoje, uma parte da sociedade brasileira rejeita e renega ainda está ali, vivo e pregnante, é porque existe uma força a mais; uma força mais eficaz que todas as boas palavras da dita boa moral, que age e permite a perenidade da cultura dos rejeitados e dos excluídos sociais. Esta força parece ser a força de tudo aquilo que vive e sobrevive na clandestinidade. Um tipo de força de rato, subterrânea e escondida, que encontra sua renovação no fato mesmo de se constituir nos domínios da obscuridade. A força vital da exclusão e do oculto.

Do ponto de vista dos dominantes, as figuras de abjeção, mesmo quando persistem e voltam, não podem ser aceitas e é por esta razão que Reginaldo Prandi (1996, p. 139) as chama de "Faces inconfessas do Brasil". Agora, se partirmos do ponto de vista dos seres abjetos, daqueles que resistem, que se transformam e assumem sua condição de "agentes do mal" para reconfigurar sua própria força vital, poderemos, em vez de falar de faces inconfessas falar de faces ocultas que não podem sobreviver senão nos territórios da obscuridade. Na obscuridade das periferias afastadas, dos becos sombrios, ladeiras, zonas do baixo meretrício e nos terreiros de periferia. Todos esses lugares que a boa sociedade não frequenta.

Essa resistência no universo oculto se dá pelo riso, 0 deboche, a autocrítica, mas também pela festa, pela música e pela alegria de viver. Nos três filmes estudados, o personagem de Madame Satã é 0 melhor exemplo dessa aceitação e reconfiguração de um discurso autocrítico: eu sou o mal, sou negro, transformista, homossexual, pobre, mas eu rio, danço e canto e me chamo Madame Satã. 
0 personagem de Nhõ João, por sua vez, afirma sua resistência ao adotar uma atitude pacífica e ao aceitar proteger por trás das aparências da religião católica e do espiritismo sua verdadeira fé. É o que se chama no Brasil de "sincretismo religioso". Fortemente criticado pelas reivindicações do movimento negro que apela a assumir as práticas religiosas de origem africana, o sincretismo é percebido por outros como uma reconfiguração brasileira de práticas e crenças vindas de outro lugar. Primeiro argumento: se os deuses africanos persistem hoje no Brasil enquanto desaparecem quase que totalmente na África, é graças às adaptações que foram feitas inclusive ao sincretismo. Segundo argumento: os escravos africanos são de origens diversas na África e sua cultura não era homogênea; transformações, hibridações e numerosas adaptações deram lugar ao que nomeamos hoje de cultura afro-brasileira, que inclui práticas religiosas diversificadas. Terceiro argumento: 0 sincretismo permite compreender que as práticas religiosas são adaptáveis e que a fé se sobrepõe aos dogmas.

Nhõ João compreendeu que uma igreja consagrada à Bom Jesus do Bomfim seria uma via de acesso e aceitação das suas práticas. Mas qual era de fato a origem de seus poderes mágicos? Africana (os deuses de suas visões)? Indígenas (os olhos e essências à base de ervas que eles usava)? Espírita (a visão da criança morta lhe indicando o lugar que a igreja deveria ser construída)? Católica (o senhor do Bomfim que ele escuta através da sua estola)?
Como vimos acima, 0 universo da religião popular e da magia no Brasil, não pertence a nenhuma população em particular, a nenhuma cor ou religião. Ele é plural e, sobretudo, popular. E é a força de resistência do povo, da grande massa dos humilhados, dos rejeitados e daqueles que constituem a "sujeira social" do país, que dá seu dinamismo a essa cultura impregnada de misticismo, de pensamento mágico, nutrida ao húmus daquilo que se oculta e não conhece nenhum limite, nem ético nem moral; o húmus da fantasia humana, para além do bem e do mal.

\section{Referências}

BRZOZOWSKI, Jerzy. Rêve exotique: Images du Brésil dans la littérature française: 1822-1888. Kraków: Abrys, 2001.

BIBLIOTECA DE AUTORES ESPAÑOLES: desde la formación del linguaje hasta nuestros dias. Madrid. Ediciones Atlas, 1945.

DEL PRIORE, M. Ao sul do corpo: condição feminina, maternidades e mentalidades no Brasil Colônia. São Paulo: Unesp, 2009.

KRISTEVA, J. Pouvoir de l'horreur: essai sur l'abjection. Paris: Seuil, 1980.

LODY, R. 7 temas da mítica afro-brasileira. Rio de Janeiro: Altiva, 1982.

MAFFESOLI, M. La part du diable: précis de subversion post-moderne. Paris: Flammarion, 2004.

MEYER, M. Maria Padilha e toda a sua quadrilha: de amante de um rei de Castela a pombagira de Umbanda. São Paulo: Duas cidades, 1993.

MORIN, E. L'esprit du temps: culture de masse au XX siècle. 1. Neurose. Paris: Grasset, 1962. 
MORIN, E.; HEINRBERG, I. 0 método I. A natureza

da natureza. Tomo 1. Porto Alegre: Sulina, 2002.

PRANDI, R. Herdeiras do Axé. São Paulo, Hucitec, 1996.

SLOTERDIJK, P. Bubbles: Spheres Volume I:

Microspherology. Cambridge: MIT Press, 2011.

SOUZA, L. M. 0 diabo e a terra de Santa Cruz:

feitiçaria e religiosidade popular no Brasil colonial.

São Paulo: Companhia das Letras, 1986.

. Inferno atlântico: demonologia e

colonização no Brasil dos séculos XVI a XVIII. São

Paulo: Companhia das Letras, 1993. 
The imaginary of evil in brazilian cinema: Abject figures of society and their mode of circulation

\section{Abstract}

The article aims to observe the paths of movement of some abject figures considered by the Brazilian cultural imaginary: Exu and Pomba-gira, and their relationships with what we call here "social garbage". We follow these characters through the figures of three Brazilian movies: Madame Satã, Cidade de Deus and Cafundó. Starting from the idea of Circulation, from which the understanding of the way things are done are complex and difficult to grasp, we use a social-historical perspective, but also symbolic-cultural. We conclude that the hidden is a enhancer force that allows the resistance, recurrence and resurgence of abject figures that nourish the imagination of Brazilian evil. Finally, we open the perspective of joy as a driving force that empowered the hidden.

\section{Keywords}

Imaginary of Evil. Abjection. Pomba-gira.

Cinema. Circulation.

\section{El imaginario del mal en el cine} brasileño: las figuras abyectas de la sociedad y su forma de circulación

\section{Resumen}

El artículo tiene como objetivo observar las trayectorias de movimiento de algunas figuras abyectas consideradas por el imaginario cultural brasileño: Exu y Pomba-gira, y su relación con lo que aquí llamamos "basura social." Seguimos estos personajes a través de las figuras de tres filmes brasileños: Madame Satã, Ciudad de Dios y Cafundó. Partiendo de la idea de circulación, por lo que la comprensión del camino hecho por las cosas es compleja y difícil de entender, utilizamos una perspectiva histórico-social, sino también simbólico-cultural. Llegamos a la conclusión de que el potenciador es una fuerza oculta que permite la resistencia, la recurrencia y la reaparición de figuras abyectas que nutren la imaginación del mal brasileña. Finalmente, abrimos la perspectiva de la alegría como una fuerza impulsora que dio poder a lo oculto.

\section{Palabras-Clave}

Imaginario del Mal. Abyección. Pomba-gira.

Cine. Circulación. 


\section{Expediente}

A revista E-Compós é a publicação científica em formato eletrônico da Associação Nacional dos Programas de Pós-Graduação em Comunicação (Compós). Lançada em 2004, tem como principal finalidade difundir a produção acadêmica de pesquisadores da área de Comunicação, inseridos em instituições do Brasil e do exterior.

\section{E-COMPÓS I www.e-compos.org.br I E-ISSN 1808-2599}

Revista da Associação Nacional dos Programas

de Pós-Graduação em Comunicacão.

Brasília, v.17, n.1, jan./abri. 2014.

A identificação das edições, a partir de 2008

passa a ser volume anual com três números.

\section{CONSELHO EDITORIAL}

Afonso Albuquerque, Universidade Federal Fluminense, Brasil Alberto Carlos Augusto Klein, Universidade Estadual de Londrina, Brasil Alex Fernando Teixeira Primo, Universidade Federal do Rio Grande do Sul, Brasil Ana Carolina Damboriarena Escosteguy, Pontifícia Universidade Católica do Rio Grande do Sul, Brasi

Ana Gruszynski, Universidade Federal do Rio Grande do Sul, Brasil Ana Silvia Lopes Davi Médola, Universidade Estadual Paulista, Brasil André Luiz Martins Lemos, Universidade Federal da Bahia, Brasi Ângela Freire Prysthon, Universidade Federal de Pernambuco, Brasil Antônio Fausto Neto, Universidade do Vale do Rio dos Sinos, Brasil Antonio Carlos Hohlfeldt, Pontifícia Universidade Católica do Rio Grande do Sul, Brasil Antonio Roberto Chiachiri Filho, Faculdade Cásper Líbero, Brasi Arlindo Ribeiro Machado, Universidade de São Paulo, Brasil Arthur Autran Franco de Sá Neto, Universidade Federal de São Carlos, Brasil Benjamim Picado, Universidade Federal Fluminense, Brasil César Geraldo Guimarães, Universidade Federal de Minas Gerais, Brasil Cristiane Freitas Gutfreind, Pontifícia Universidade Católica do Rio Grande do Sul, Brasil Denilson Lopes, Universidade Federal do Rio de Janeiro, Brasil Denize Correa Araujo, Universidade Tuiuti do Paraná, Brasi Edilson Cazeloto, Universidade Paulista , Brasil

Eduardo Vicente, Universidade de São Paulo, Brasil Eneus Trindade, Universidade de São Paulo, Brasil Erick Felinto de Oliveira, Universidade do Estado do Rio de Janeiro, Brasi Florence Dravet, Universidade Católica de Brasília, Brasil Gelson Santana, Universidade Anhembi/Morumbi, Brasi Gilson Vieira Monteiro, Universidade Federal do Amazonas, Brasil Gislene da Silva, Universidade Federal de Santa Catarina, Brasil Guillermo Orozco Gómez, Universidad de Guadalajara Gustavo Daudt Fischer, Universidade do Vale do Rio dos Sinos, Brasil Hector Ospina, Universidad de Manizales, Colômbia Herom Vargas, Universidade Municipal de São Caetano do Sul, Brasil Ieda Tucherman, Universidade Federal do Rio de Janeiro, Brasil Inês Vitorino, Universidade Federal do Ceará, Brasil Janice Caiafa, Universidade Federal do Rio de Janeiro, Brasil Jay David Bolter, Georgia Institute of Technology Jeder Silveira Janotti Junior, Universidade Federal de Pernambuco, Brasi João Freire Filho, Universidade Federal do Rio de Janeiro, Brasil John DH Downing, University of Texas at Austin, Estados Unidos
José Afonso da Silva Junior, Universidade Federal de Pernambuco, Brasil José Carlos Rodrigues, Pontifícia Universidade Católica do Rio de Janeiro, Brasil José Luiz Aidar Prado, Pontifícia Universidade Católica de São Paulo, Brasil José Luiz Warren Jardim Gomes Braga, Universidade do Vale do Rio dos Sinos, Brasil Juremir Machado da Silva, Pontifícia Universidade Católica do Rio Grande do Sul, Brasil Laan Mendes Barros, Universidade Metodista de São Paulo, Brasi Lance Strate, Fordham University, USA, Estados Unidos Lorraine Leu, University of Bristol, Grã-Bretanha Lucia Leão, Pontifícia Universidade Católica de São Paulo, Brasil Luciana Panke, Universidade Federal do Paraná, Brasil Luiz Claudio Martino, Universidade de Brasília, Brasil Malena Segura Contrera, Universidade Paulista, Brasil Márcio de Vasconcellos Serelle, Pontifícia Universidade Católica de Minas Gerais, Brasil Maria Aparecida Baccega, Universidade de São Paulo e Escola Superior de Propaganda e Marketing, Brasil Maria das Graças Pinto Coelho, Universidade Federal do Rio Grande do Norte, Brasil Maria Immacolata Vassallo de Lopes, Universidade de São Paulo, Brasil Maria Luiza Martins de Mendonça, Universidade Federal de Goiás, Brasil Mauro de Souza Ventura, Universidade Estadual Paulista, Brasil Mauro Pereira Porto, Tulane University, Estados Unidos Nilda Aparecida Jacks, Universidade Federal do Rio Grande do Sul, Brasil Paulo Roberto Gibaldi Vaz, Universidade Federal do Rio de Janeiro, Brasil Potiguara Mendes Silveira Jr, Universidade Federal de Juiz de Fora, Brasil Renato Cordeiro Gomes, Pontifícia Universidade Católica do Rio de Janeiro, Brasil Robert K Logan, University of Toronto, Canadá

Ronaldo George Helal, Universidade do Estado do Rio de Janeiro, Brasil Rosana de Lima Soares, Universidade de São Paulo, Brasil Rose Melo Rocha, Escola Superior de Propaganda e Marketing, Brasil Rossana Reguillo, Instituto de Estudos Superiores do Ocidente, Mexico Rousiley Celi Moreira Maia, Universidade Federal de Minas Gerais, Brasi Sebastião Carlos de Morais Squirra, Universidade Metodista de São Paulo, Brasil Sebastião Guilherme Albano da Costa, Universidade Federal do Rio Grande do Norte, Brasil

Simone Maria Andrade Pereira de Sá, Universidade Federal Fluminense, Brasi Tiago Quiroga Fausto Neto, Universidade de Brasília, Brasil Suzete Venturelli, Universidade de Brasília, Brasil Valerio Fuenzalida Fernández, Puc-Chile, Chile Veneza Mayora Ronsini, Universidade Federal de Santa Maria, Brasil Vera Regina Veiga França, Universidade Federal de Minas Gerais, Brasil

\section{COMISSÃO EDITORIAL}

Cristiane Freitas Gutfreind I Pontifícia Universidade Católica do Rio Grande do Sul, Brasil Irene Machado I Universidade de São Paulo, Brasil

Jorge Cardoso Filho I Universidade Federal do Reconcavo da Bahia, Brasil / Universidade Federal da Bahia, Brasil

CONSULTORES AD HOC

Adriana Amaral, Universidade do Vale do Rio dos Sinos, Brasil

Alexandre Rocha da Silva, Universidade Federal do Rio Grande do Sul, Brasi Arthur Ituassu, Pontifícia Universidade Católica do Rio de Janeiro, Brasil Bruno Souza Leal, Universidade Federal de Minas Gerais, Brasil Elizabeth Bastos Duarte, Universidade Federal de Santa Maria, Brasil Francisco Paulo Jamil Marques, Universidade Federal do Ceará, Brasi Maurício Lissovsky, Universidade Federal do Rio de Janeiro, Brasil Suzana Kilpp, Universidade do Vale do Rio dos Sinos, Brasil Vander Casaqui, Escola Superior de Propaganda e Marketing, Brasil

EDIÇÃO DE TEXTO E RESUMOS I Susane Barros SECRETÁRIA EXECUTIVA I Helena Stigger EDITORAÇÃo ELETRÔNICA I Roka Estúdio
COMPÓS I www.compos.org.br

Associação Nacional dos Programas de Pós-Graduação em Comunicação

Presidente

Eduardo Morettin

Universidade de São Paulo, Brasil

eduardomorettin@usp.br

Vice-presidente

Inês Vitorino

Universidade Federal do Ceará, Brasil

ines@ufc.br

Secretária-Geral

Gislene da Silva

Universidade Federal de Santa Catarina, Brasil

gislenedasilva@gmail.com 